\title{
ASURANSI JIWA ENDOWMENT DENGAN PENGEMBALIAN PREMI MENGGUNAKAN SIMULASI MONTE CARLO
}

\author{
Made Edi Hendrawan ${ }^{1 \S}$, I Nyoman Widana ${ }^{2}$, Ketut Jayanegara ${ }^{3}$ \\ ${ }^{1}$ Program Studi Matematika, Fakultas MIPA - Universitas Udayana [Email: madeedihendrawan@gmail.com] \\ ${ }^{2}$ Program Studi Matematika, Fakultas MIPA - Universitas Udayana [Email: nwidana@yahoo.com] \\ ${ }^{3}$ Program Studi Matematika, Fakultas MIPA - Universitas Udayana [Email: ktjayanegara@unud.ac.id] \\ ${ }^{\S}$ Corresponding Author
}

\begin{abstract}
Premium refunds are a sum of the money returned to the insured. The purpose of this study was to compare the premium of endowment life insurance with premium refund on constant interest rates numerical calculations and using Monte Carlo simulations. Gompertz distribution was used to obtain the mortality rates. The results showed that the premiums generated by Monte Carlo simulations for insurance participants issued under 45 years will be more expensive than the ones which were generated by numerical calculations. However, the premiums generated by Monte Carlo simulations for insurance participants issued above 45 years will be cheaper than the ones which were generated by numerical calculations.
\end{abstract}

Keywords: Premium refunds, constant interest rates, distribution Gompertz, Monte Carlo.

\section{PENDAHULUAN}

Asuransi jiwa endowment adalah salah satu jenis asuransi jiwa yang memberikan nilai tunai manfaat kepada pihak tertanggung sekaligus investasi. Setiap orang yang mengikuti asuransi wajib membayar premi. Premi merupakan sejumlah uang yang wajib dibayarkan pihak tertanggung kepada pihak penanggung sesuai dengan kontrak asuransi yang telah disepakati. Salah satu fitur yang ditawarkan perusahaan adalah fitur asuransi pengembalian premi. Pengembalian premi merupakan sejumlah uang pertanggungan yang dikembalikan kepada pihak tertanggung. Terdapat beberapa faktor yang harus diperhatikan dalam perhitungan premi asuransi jiwa, yaitu: biaya perusahaan, tingkat kematian dan tingkat suku bunga (Sembiring, 1986).

Sari (2016) telah melakukan perhitungan premi asuransi jiwa endowment suku bunga vasicek secara numerik menghasilkan nilai premi yang tidak jauh berbeda dengan nilai premi yang dihitung menggunakan simulasi monte carlo. Sementara itu, di dalam asuransi ada yang namanya pengembalian premi dan sejauh ini penelitian mengenai perhitungan premi asuransi jiwa endowment dengan pengembalian premi menggunakan simulasi monte carlo belum pernah dilakukan. Simulasi Monte Carlo adalah suatu metode simulasi untuk mengevaluasi suatu model deterministik yang melibatkan bilangan acak sebagai salah satu input. (Rubinstein, 1981).

Penulis ingin melakukan penelitian perhitungan asuransi jiwa endownment dengan pengembalian premi tanpa dan mengunakan simulasi monte carlo. Selanjutnya akan dibahas perbandingan hasil perhitungan asuransi jiwa endownment pengembalian premi tanpa dan dengan menggunakan Simulasi Monte Carlo.

Pada penelitian ini akan dikaji perhitungan premi asuransi jiwa endowment dengan pengembalian premi suku bunga konstan simulasi Monte Carlo. Selanjutnya akan dibahas perbandingan hasil perhitungan premi asuransi jiwa endowment dengan pengembalian premi suku bunga konstan tanpa dan menggunakan simulasi monte carlo.

Adapun tujuan dari penelitian adalah: 
1. Untuk mengetahui hasil dari perhitungan asuransi jiwa endowment dengan pengembalian premi tanpa dan menggunakan simulasi Monte Carlo.

2. Untuk mengetahui perbandingan hasil perhitungan dari asuransi jiwa endowment dengan pengembalian premi tanpa dan menggunakan simulasi Monte Carlo.

Konsep-konsep yang digunakan untuk menentukan premi asuransi jiwa endowment dengan pengembalian premi tanpa dan menggunakan simulasi Monte Carlo.

Peluang seseorang berusia $x$ tahun akan tetap hidup hingga mencapai usia $x+t$ tahun dinotasikan dengan ${ }_{t} p_{x}$ dan peluang seseorang berusia $x$ tahun akan meninggal sebelum usia $x+t$ tahun dinotasikan dengan ${ }_{t} q_{x}$ yang secara berturut-turut didefinisikan sebagai (Bowers et al, 1997):

$$
\begin{aligned}
{ }_{t} p_{x} & =P\left[T_{x}>t\right], t \geq 0 \\
{ }_{t} q_{x} & =P\left[T_{x} \leq t\right]=1-{ }_{t} p_{x} t \geq 0
\end{aligned}
$$

Distribusi Gompertz merupakan salah satu distribusi yang sering digunakan dalam menggambarkan usia kematian seseorang. Fungsi peluang ${ }_{t} p_{x}$ dan ${ }_{t} q_{x}$ menurut fungsi distribusi Gompertz yaitu (Dickson et al, 2011):

$$
\begin{aligned}
{ }_{t} p_{x} & =\exp \left[-\frac{B c^{x}}{\ln c}\left(c^{t}-1\right)\right] \\
{ }_{t} q_{x} & =1-\exp \left[-\frac{B c^{x}}{\ln c}\left(c^{t}-1\right)\right]
\end{aligned}
$$

Jumlah seseorang berusia $x+t+1$ tahun apabila diketahui jumlah seseorang berusia $x+t$ tahun dan peluang seseorang berusia $x+t$ tahun akan tetap hidup hingga mencapai usia $x+t+1$ tahun adalah (Futami, 1993):

$$
\begin{aligned}
& l_{x+t+1}=l_{x+t} \cdot p_{x+t} \\
&=l_{x} \cdot t+1 \\
& p_{x}
\end{aligned}
$$

Lebih lanjut lagi, peluang seseorang berusia $x+t$ tahun akan meninggal sebelum usia $x+t+1$ tahun dinotasikan dengan $q_{x+t}$ dan dirumuskan sebagai (Futami, 1993):

$$
q_{x+t}=1-\frac{l_{x+t+1}}{l_{x+t}}
$$

Asuransi jiwa endowment merupakan perpaduan antara asuransi jiwa berjangka dan asuransi jiwa dwiguna murni. Apabila tertanggung meninggal selama jangka waktu kontrak misalkan $t$ tahun, maka pada pewarisnya akan dibayarkan uang pertanggungan, namun apabila tertanggung dapat mencapai usia $x+t$ tahun, maka kepadanya akan dibayarkan uang pertanggungan pada akhir tahun $x+t$ (Sembiring, 1986).

Nilai tunai manfaat merupakan sejumlah uang yang diterima pihak tertanggung pada saat melakukan klaim. Actuarial Present Value untuk manfaat asuransi jiwa endowment dinotasikan dengan $A_{x: \bar{n}}$ dan didefinisikan sebagai (Bowers et al, 1997) :

$$
A_{\overline{x: n\rceil}}=\sum_{k=0}^{n-1} v^{k+1}{ }_{k} p_{x} q_{x+k}+v^{n}{ }_{n} p_{x}
$$

Anuitas adalah suatu pembayaran dalam jumlah tertentu yang dilakukan setiap selang waktu dan jangka waktu tertentu, secara berkelanjutan (Futami, 1993). Actuarial Present Value dari anuitas asuransi jiwa endowment dinotasikan dengan $\ddot{a}_{x \bar{n} \overline{1}}$ dan didefinisikan sebagai (Dickson et al, 2013):

$$
\ddot{a}_{x: \bar{\eta}}=\sum_{k=0}^{n-1} v_{k}^{k} p_{x}
$$

Pada perhitungan premi asuransi, premi dibayarkan oleh pihak tertanggung sehingga ekspektasi nilai tunai dari kerugian finansial yang diderita oleh pihak penanggung pada saat polis dikeluarkan sama dengan nol. Untuk merumuskan prinsip diatas, didefinisikan besar kerugian pihak penanggung dengan $L$ yang merupakan variabel acak dari nilai tunai manfaat yang dibayarkan oleh pihak penanggung dikurangi variabel acak nilai tunai anuitas dari premi yang dibayarkan oleh pihak tertanggung. Prinsip diatas disebut prinsip ekuivalensi dan mempunyai persamaan sebagai berikut (Dickson et al, 2013):

$$
E(L)=0
$$

Untuk asuransi jiwa endowment $\mathrm{n}$ tahun dengan nilai manfaat sebesar 1 rupiah, nilai $L=1 . v^{\min (K+1, n)}-P . \ddot{a}_{\min (K+1, n)}$. Dengan mensubstitusi nilai $L$ ke persamaan (9) diperoleh $E\left(1 . v^{\min (K+1, n)}-P . \ddot{a}_{\min (K+1, n)}\right)=0$ 


$$
\begin{aligned}
E\left(1 . v^{\min (K+1, n)}\right) & =P . \ddot{a}_{\min (K+1, n)} \\
A \overline{x: n]} & =P \ddot{a}_{x: \bar{n}} \\
P & =\frac{A_{\overline{x: n}}}{\ddot{a}_{x: n]}}
\end{aligned}
$$

Selanjutnya, premi tahunan asuransi jiwa endowment dapat diperoleh dengan mensubstitusikan persamaan (7) dan (8) ke persamaan (10) yaitu:

$$
P=\frac{\sum_{k=0}^{n-1} v_{k}^{k+1} p_{x} q_{x+k}+v^{n}{ }_{n} p_{x}}{\sum_{k=0}^{n-1} v_{k}^{k} p_{x}}
$$

Nilai pengembalian premi merupakan merupakan sejumlah uang pertanggungan yang diterima pihak tertanggung pada saat melakukan klaim. Actuarial Present Value (APV) asuransi berjangka $n$ tahun dengan manfaat per 1 rupiah yang meningkat setiap tahun adalah

$$
(I A)_{\overline{x: n\rceil}}=E[Z]=\sum_{k=0}^{n-1}(k+1) v_{k}^{k+1} \mid q_{x}
$$

Bentuk kontrak asuransi gabungan yang lain misalnya jika pihak tertanggung meninggal pada tahun polis ke- $t$, maka semua premi yang telah dibayar sampai tahun ke- $t$ dikembalikan. Misal premi netto standar yang dikembalikan $P$ menjadi (Futami, 1993):

$$
P=\frac{A_{x: n]}}{\ddot{a}_{x: \bar{n}\rceil}-(I A)_{x: n]}}
$$

Simulasi Monte Carlo adalah suatu metode simulasi untuk mengevaluasi suatu model deterministik yang melibatkan bilangan acak sebagai salah satu input. Salah satu metode yang digunakan dalam simulasi Monte Carlo adalah metode transformasi invers Metode ini memudahkan kita untuk membuat simulasi amatan dari suatu variabel acak $T$ ketika kita menggunakan pembangkit bilangan acak yang berdistribusi seragam $U(0,1)$.

Metode transformasi invers menyatakan jika $F(t)=P(T \leq t)$ dan $u$ adalah suatu bilangan acak yang diambil dari $U(0,1)$, maka (Dickson et al, 2013):

$$
\begin{aligned}
t & =F^{-1}(u) \\
& =\frac{1}{\log c}\left(\log \left(1-\frac{\log (c) \log (1-u)}{B c^{x}}\right)\right)
\end{aligned}
$$

\section{METODE PENELITIAN}

Penelitian ini menggunakan data sekunder yaitu data yang terdapat dalam Tabel Mortalita Indonesia tahun 2011. Pengolahan data pada penelitian ini menggunakan alat bantu Software Microsoft Excell.

Adapun tahap-tahap analisis data yang digunakan dalam penelitian ini adalah sebagai berikut:

1. Estimasi parameter distribusi Gompertz.

2. Melakukan simulasi perhitungan premi untuk peserta asuransi usia $30,35,40,45,50,55$ dan 60 tahun menggunakan metode numerik (tanpa simulasi Monte Carlo) untuk suku bunga konstan yaitu dengan langkahlangkah:

a. Menentukan nilai ${ }_{k} p_{x}, l_{x+k+1}$ dan $q_{x+k}$ menggunakan distribusi Gompertz.

b. Menghitung nilai tunai manfaat asuransi jiwa endowment suku bunga konstan berjangka $n$-tahun.

c. Menghitung nilai tunai anuitas asuransi jiwa endowment suku bunga konstan berjangka $n$-tahun.

d. Menghitung nilai pengembalian premi asuransi jiwa endowment suku bunga konstan berjangka $n$-tahun.

e. Menghitung nilai premi asuransi jiwa endowment dengan pengembalian premi suku bunga konstan berjangka $n$-tahun.

3. Melakukan simulasi perhitungan premi untuk peserta asuransi usia 30, 35, 40, 45, 50, 55 dan 60 tahun menggunakan simulasi Monte Carlo dengan langkah-langkah:

a. Membangkitkan bilangan acak dengan distribusi $U(0,1)$.

b. Menghitung sisa usia pihak tertanggung $(t)$.

c. Menghitung floor dari sisa usia pihak tertanggung $(t)$ yang diperoleh pada langkah (3.b).

d. Menghitung nilai tunai manfaat asuransi jiwa endowment suku bunga konstan berjangka $n$-tahun.

e. Menghitung nilai tunai anuitas asuransi jiwa endowment suku bunga konstan berjangka $n$-tahun. 
f. Menghitung nilai pengembalian premi asuransi jiwa endowment suku bunga konstan berjangka $n$-tahun.

g. Menghitung nilai premi asuransi jiwa endowment dengan pengembalian premi suku bunga konstan berjangka $n$-tahun.

4. Membandingkan hasil perhitungan asuransi jiwa endownment dengan pengembalian premi tanpa simulasi monte carlo pada langkah (2.e) dan dengan simulasi monte carlo pada langkah (3.g).

\section{HASIL DAN PEMBAHASAN}

Berdasarkan persamaan (4) yang merupakan peluang pihak tertanggung berusia $x$ tahun meninggal sebelum mencapai usia $x+t$ tahun menurut fungsi distribusi Gompertz, dihitung nilai $t=1$, sehingga diperoleh:

$$
q_{x}=1-\exp \left[-\frac{B c^{x}}{\ln c}(c-1)\right]
$$

Selanjutnya dengan menggunakan persamaan (20) dicari nilai parameter $B$ dan $c$ sebagai berikut:

$$
\begin{aligned}
1-q_{x} & =\exp \left[-\frac{B c^{x}}{\ln c}(c-1)\right] \\
\ln \left(1-q_{x}\right) & =-\frac{B c^{x}}{\ln c}(c-1) \\
\ln \left(\ln \frac{1}{\left(1-q_{x}\right)}\right) & =x \ln c+\ln \left(\frac{B(c-1)}{\ln c}\right)
\end{aligned}
$$

Apabila dimisalkan:

$$
\begin{aligned}
& y=\ln \left(\ln \frac{1}{\left(1-q_{x}\right)}\right) \\
& a=\ln c \\
& b=\ln \left(\frac{B(c-1)}{\ln c}\right)
\end{aligned}
$$

maka persamaan (16) dapat ditulis dalam bentuk persamaan linier sebagai:

$$
y=a x+b
$$

Berdasarkan persamaan (17), dengan menggunakan data $q_{x}$ yang terdapat dalam Tabel Mortalita Indonesia 2011 dan bantuan software Microsoft Excell diperoleh bentuk persamaan linier dari distribusi Gompertz yaitu $y=0.09635 x-10.1536$. Sehingga diperoleh nilai parameter $B=0.0000370912$ dan $c=1.1011144$.

Dengan menggunakan nilai $B$ dan $c$ yang diperoleh, maka persamaan (4) dapat ditulis sebagai:

$$
{ }_{k} q_{x}=1-\exp \left[-\frac{0.0000370912 \times(1.101144)^{x}}{0.09635} \times\right.
$$

Langkah selanjutnya adalah melakukan simulasi perhitungan premi. Simulasi perhitungan premi dilakukan untuk pihak tertanggung berusia 30, 35, 40, 45, 50, 55 dan 60 tahun. Simulasi dilakukan tanpa dan dengan menggunakan simulasi Monte Carlo. Pada penelitian ini dihitung untuk pembayaran premi yang dilakukan setiap tahun selama jangka waktu kontrak asuransi dan pihak tertanggung masih hidup. Jangka waktu kontrak asuransi yang digunakan adalah 30 tahun dengan uang pertanggungan sebesar Rp. 100.000.000,- dan suku bunga konstan sebesar $4.5 \%$.

Nilai peluang ${ }_{k} p_{x}, l_{x+k+1}$ dan $q_{x+k}$ secara berturut-turut dapat ditentukan berdasarkan persamaan (18), (5) dan (6). Nilai-nilai peluang tersebut selanjutnya digunakan untuk menghitung nilai tunai manfaat, nilai tunai anuitas, nilai pengembalian premi dan nilai premi asuransi jiwa endowment suku bunga konstan tanpa simulasi Monte Carlo.

Nilai tunai manfaat asuransi jiwa endowment suku bunga konstan tanpa simulasi Monte Carlo dapat ditentukan menggunakan persamaan (17). Nilai tunai manfaat dihitung berdasarkan nilai-nilai peluang distribusi Gompertz. Hasil perhitungan nilai tunai manfaat asuransi jiwa endowment suku bunga konstan tanpa menggunakan simulasi Monte Carlo dapat dilihat pada Tabel 1.

Tabel 1. Nilai Tunai Manfaat Tanpa Simulasi Monte Carlo

\begin{tabular}{|c|c|}
\hline Usia & Gompertz \\
\hline 30 & 0.2826512 \\
\hline 35 & 0.2919394 \\
\hline 40 & 0.3063690 \\
\hline 45 & 0.3282523 \\
\hline 50 & 0.3602411 \\
\hline 55 & 0.4045457 \\
\hline 60 & 0.4615300 \\
\hline
\end{tabular}

Nilai tunai anuitas asuransi jiwa endowment suku bunga konstan dapat ditentukan menggunakan persamaan (18). Nilai tunai 
anuitas juga dihitung berdasarkan nilai-nilai peluang distribusi Gompertz. Hasil perhitungan nilai tunai anuitas asuransi jiwa endowment suku bunga kosntan tanpa menggunakan simulasi Monte Carlo dapat dilihat pada Tabel 2.

Tabel 2. Nilai Tunai Anuitas Tanpa Simulasi Monte Carlo

\begin{tabular}{|c|c|}
\hline Usia & Gompertz \\
\hline 30 & 16.6584323 \\
\hline 35 & 16.4427400 \\
\hline 40 & 16.1076500 \\
\hline 45 & 15.5994700 \\
\hline 50 & 14.8566200 \\
\hline 55 & 13.8277700 \\
\hline 60 & 12.5044700 \\
\hline
\end{tabular}

Nilai pengembalian premi asuransi jiwa endowment suku bunga konstan dapat ditentukan menggunakan persamaan (12). Nilai pengembalian premi juga dihitung berdasarkan nilai-nilai peluang distribusi Gompertz. Hasil perhitungan nilai pengembalian premi asuransi jiwa endowment suku bunga kosntan tanpa menggunakan simulasi Monte Carlo dapat dilihat pada Tabel 3.

Tabel 3. Nilai pengembalian premi Tanpa

\begin{tabular}{|c|c|}
\multicolumn{2}{c|}{ Simulasi } \\
\hline Usia & Gonte Carlo \\
\hline 30 & 0.8613860 \\
\hline 35 & 1.3434100 \\
\hline 40 & 2.0490667 \\
\hline 45 & 3.0189560 \\
\hline 50 & 4.2203313 \\
\hline 55 & 5.4684117 \\
\hline 60 & 6.4070253 \\
\hline
\end{tabular}

Nilai premi asuransi jiwa endowment suku bunga konstan dapat ditentukan berdasarkan persamaan (13) dengan nilai tunai manfaat, nilai tunai anuitas dan nilai pengembalian premi secara berturut-turut dapat dilihat pada Tabel 1, Tabel 2 dan Tabel 3. Hasil perhitungan premi asuransi jiwa endowment suku bunga konstan tanpa simulasi Monte Carlo dengan uang pertanggungan sebesar Rp. 1,- dapat dilihat pada Tabel 4.
Tabel 4. Premi Tanpa Simulasi Monte Carlo

\begin{tabular}{|c|c|}
\hline Usia & Gompertz \\
\hline 30 & 0.0178926 \\
\hline 35 & 0.0193346 \\
\hline 40 & 0.0217923 \\
\hline 45 & 0.0260921 \\
\hline 50 & 0.0338690 \\
\hline 55 & 0.0483943 \\
\hline 60 & 0.0756924 \\
\hline
\end{tabular}

Dengan uang pertanggungan sebesar Rp. 100.000.000,- maka nilai premi yang harus dibayarkan pihak tertanggung berusia 30 tahun menggunakan distribusi Gompertz sebesar Rp. 1.789.260,-

Langkah pertama dalam melakukan perhitungan premi asuransi jiwa endowment suku bunga konstan menggunakan simulasi Monte Carlo adalah membangkitkan bilangan acak berdistribusi $U(0,1)$ sebanyak 1000 dengan bantuan software Microsoft Excell, namakan $u_{1}, u_{2}, \ldots, u_{1000}$. Selanjutnya menentukan sisa usia dari pihak tertanggung $(t)$.

Sisa usia pihak tertanggung $(t)$ dapat ditentukan berdasarkan persamaan (14) dengan nilai-nilai parameter distribusi Gompertz yaitu $B=0.0000370$ dan $c=1.1011440$, sehingga persamaan (14) dapat ditulis sebagai: $t=F^{-1}(u)$

$=\frac{1}{\log 1.101144}\left(\log \left(1-\frac{\log (1.101144) \log (1-u)}{(0.0000370)(1.101144)^{x}}\right)\right)$ dengan $u$ merupakan bilangan acak berdistribusi $U(0,1)$.

Nilai $t_{1}, t_{2}, \ldots, t_{1000}$ dihitung untuk pihak tertanggung berusia 30, 35, 40, 45, 50, 55 dan 60 tahun. Setelah diperoleh nilai $t_{1}, t_{2}, \ldots, t_{1000}$, langkah selanjutnya adalah mencari nilai floor dari $t_{1}, t_{2}, \ldots, t_{1000}$. Untuk memudahkan perhitungan, dimisalkan nilai $\left\lfloor t_{1}\right\rfloor,\left\lfloor t_{2}\right\rfloor, \ldots,\left\lfloor t_{1000}\right\rfloor=k_{1}, k_{2}, \ldots, k_{1000}$ Apabila nilai floor dari sisa usia pihak tertanggung yang diperoleh melebihi jangka waktu kontrak asuransi, maka digunakan nilai pada batas akhir kontrak asuransi tersebut. Namun, apabila nilai floor dari sisa usia pihak tertanggung kurang atau sama dengan jangka waktu kontrak asuransi, maka digunakan nilai floor dari sisa usia pihak tertanggung itu sendiri. 
Nilai dari $k_{1}, k_{2}, \ldots, k_{1000}$ yang diperoleh selanjutnya digunakan dalam perhitungan nilai tunai manfaat, nilai tunai anuitas, nilai pengembalian premi dan nilai premi asuransi jiwa endowment suku bunga konstan menggunakan simulasi Monte Carlo yang secara berturut-turut dinotasikan dengan $A_{M C}$, $\ddot{a}_{M C},(I A)_{M C}$ dan $P_{M C}$.

Nilai tunai manfaat asuransi jiwa endowment suku bunga konstan menggunakan simulasi Monte Carlo dihitung dengan simulasi sebanyak 1000 dan dirumuskan sebagai:

$$
A_{M C}=\frac{1}{5000}\left[\sum_{i=1, k i}^{1000} A_{\overline{x: n\rceil}}\right]
$$

Berdasarkan persamaan (19), dihitung nilai tunai manfaat asuransi jiwa endowment suku bunga konstan dengan simulasi Monte Carlo untuk pihak tertanggung berusia $30,35,40,45$, 50, 55 dan 60 tahun.

Hasil perhitungan nilai tunai manfaat asuransi jiwa endowment suku bunga konstan dengan simulasi Monte Carlo dapat dilihat pada Tabel 5.

Tabel 5. Nilai Tunai Manfaat dengan Simulasi Monte Carlo.

\begin{tabular}{|c|c|}
\hline Usia & Nilai Tunai Manfaat \\
\hline 30 & 0.2858185 \\
\hline 35 & 0.2959330 \\
\hline 40 & 0.3100474 \\
\hline 45 & 0.3310737 \\
\hline 50 & 0.3617062 \\
\hline 55 & 0.4048423 \\
\hline 60 & 0.4602049 \\
\hline
\end{tabular}

Berdasarkan Tabel 5 dapat dilihat bahwa semakin tinggi usia pihak tertanggung yang mengikuti asuransi, maka nilai tunai manfaat yang diperoleh akan semakin besar.

Nilai tunai anuitas asuransi jiwa endowment suku bunga konstan menggunakan simulasi Monte Carlo dihitung dengan simulasi sebanyak 1000 dan dirumuskan sebagai:

$\ddot{a}_{M C}=\frac{1}{5000}\left[\sum_{i=1, k i}^{1000} \ddot{a}_{\overline{x: n\rceil}}\right]$

Berdasarkan persamaan (20), dihitung nilai tunai anuitas asuransi jiwa endowment suku bunga konstan dengan simulasi Monte Carlo untuk pihak tertanggung berusia $30,35,40,45,50,55$ dan 60 tahun.

Hasil perhitungan nilai tunai anuitasasuransi jiwa endowment suku bunga konstan dengan simulasi Monte Carlo dapat dilihat pada Tabel 6 .

Tabel 6. Nilai Tunai anuitas dengan Simulasi Monte Carlo.

\begin{tabular}{|c|c|}
\hline Usia & Nilai Tunai anuitas \\
\hline 30 & 16.5848821 \\
\hline 35 & 16.3499996 \\
\hline 40 & 16.0222319 \\
\hline 45 & 15.5339552 \\
\hline 50 & 14.8225993 \\
\hline 55 & 13.8208840 \\
\hline 60 & 12.5352409 \\
\hline
\end{tabular}

Berdasarkan Tabel 6 dapat dilihat bahwa semakin tinggi usia pihak tertanggung yang mengikuti asuransi, maka nilai tunai manfaat yang diperoleh akan semakin kecil.

Nilai pengembalian premi asuransi jiwa endowment suku bunga konstan menggunakan simulasi Monte Carlo dihitung dengan simulasi sebanyak 1000 dan dirumuskan sebagai:

$$
(I A)_{M C}=\frac{1}{5000}\left[\sum_{i=1, k i}^{1000}(I A)_{\overline{x: n\rceil}}\right]
$$

Berdasarkan persamaan (21), dihitung nilai pengembalian premi asuransi jiwa endowment suku bunga konstan dengan simulasi Monte Carlo untuk pihak tertanggung berusia 30, 35, 40, 45, 50, 55 dan 60 tahun.

Hasil perhitungan nilai pengembalian premi asuransi jiwa endowment suku bunga konstan dengan simulasi Monte Carlo dapat dilihat pada Tabel 7.

Tabel 7. Nilai pengembalian premi dengan Simulasi Monte Carlo.

\begin{tabular}{|c|c|}
\hline Usia & Nilai Tunai Manfaat \\
\hline 30 & 0.94182719 \\
\hline 35 & 1.30679347 \\
\hline 40 & 1.95597238 \\
\hline 45 & 2.89761994 \\
\hline 50 & 4.12644152 \\
\hline 55 & 5.29041387 \\
\hline 60 & 6.26311918 \\
\hline
\end{tabular}

Berdasarkan Tabel 7 dapat dilihat bahwa semakin tinggi usia pihak tertanggung yang mengikuti asuransi, maka nilai pengembalian 
premi yang diperoleh akan semakin besar.

Nilai premi asuransi jiwa endowment suku bunga konstan dengan simulasi Monte Carlo dapat ditentukan berdasarkan persamaan (13) dengan nilai tunai manfaat, nilai tunai anuitas dan nilai pengembalian premi asuransi jiwa endowment suku bunga konstan menggunakan simulasi Monte Carlo secara berturut-turut dapat dilihat pada Tabel 5, Tabel 6 dan Tabel 7. Hasil perhitungan premi asuransi jiwa endowment dengan pengembalian premi suku bunga konstan simulasi Monte Carlo dengan uang pertanggungan sebesar Rp. 1,- dapat dilihat pada Tabel 8 .

Tabel 8. Nilai Premi dengan Simulasi Monte Carlo.

\begin{tabular}{|c|c|}
\hline Usia & Nilai Premi \\
\hline 30 & 0.0182712 \\
\hline 35 & 0.0196722 \\
\hline 40 & 0.0220419 \\
\hline 45 & 0.0262001 \\
\hline 50 & 0.0338164 \\
\hline 55 & 0.0474583 \\
\hline 60 & 0.0733730 \\
\hline
\end{tabular}

Berdasarkan Tabel 8 dapat dilihat bahwa nilai premi yang harus dibayarkan pihak tertanggung berusia 30 tahun dengan uang pertanggungan Rp. 100.000.00,- adalah sebesar Rp. 1.827.120,-.

Berikut diberikan perbandingan hasil perhitungan premi asuransi jiwa endowment suku bunga konstan tanpa dan dengan simulasi Monte Carlo menggunakan distribusi Gompertz seperti pada Tabel 9.

Tabel 9. Perbandingan Hasil Perhitungan Premi dengan dan tanpa Simulasi Monte Carlo

\begin{tabular}{|c|c|c|}
\hline Usia & $\begin{array}{c}\text { Tanpa Simulasi } \\
\text { Monte Carlo }\end{array}$ & $\begin{array}{c}\text { Dengan Simulasi } \\
\text { Monte Carlo }\end{array}$ \\
\hline 30 & 0.0178926 & 0.0182712 \\
\hline 35 & 0.0193346 & 0.0196722 \\
\hline 40 & 0.0217923 & 0.0220419 \\
\hline 45 & 0.0260921 & 0.0262001 \\
\hline 50 & 0.0338690 & 0.0338164 \\
\hline 55 & 0.0483943 & 0.0474583 \\
\hline 60 & 0.0756924 & 0.0733730 \\
\hline
\end{tabular}

Berdasarkan Tabel 9 dapat dilihat bahwa nilai premi asuransi jiwa endowment yang dihitung menggunakan simulasi Monte Carlo memberikan hasil yang tidak jauh berbeda dibandingkan nilai premi yang dihitung menggunakan metode numerik (tanpa simulasi Monte Carlo) dengan tingkat ketelitian tiga angka di belakang koma.

\section{KESIMPULAN}

Kesimpulan yang dapat diperoleh dari hasil penelitian ini yaitu: sisa usia yang kurang dari masa kontrak (meninggal saat kontrak berjalan) lebih sering dibangkitkan pada simulasi Monte Carlo daripada peluang meninggal saat kontrak berjalan pada metode numerik untuk usia di bawah umur 45 tahun. Mengakibatkan nilai premi yang diperoleh dengan simulasi Monte Carlo lebih besar dari pada nilai premi yang diperoleh dengan metode numerik. Namun, hal sebaliknya terjadi untuk usia di atas umur 45 tahun. Sisa usia yang melewati masa kontak (masih hidup saat kontrak berakhir) lebih sering dibangkitkan pada simulasi Monte Carlo daripada peluang hidup saat kontrak berakhir pada metode numerik untuk usia diatas umur 45 tahun. Mengakibatkan nilai premi yang diperoleh dengan simulasi Monte Carlo lebih kecil daripada nilai premi yang diperoleh dengan metode numerik.

\section{DAFTAR PUSTAKA}

Bowers, N. L., Gerber, H.U., Hickman, J.C., Jones, D.A and Nesbitt, C.J. 1997. Actuarial Mathematic. Schaumburg: The Society of Actuaries

Dickson, D. C. M., Hardy, M. R and Waters, H. R. 2013. Actuarial Mathematic for Life Contingent Risks.

Futami, T. 1993. Matematika Asuransi Jiwa Bagian I. Tokyo: Oriental Life Insurance Cultural Development Centre.

Rubinstein, R. Y and Kroese, D. K. 2008. Simulation and The Monte Carlo Method. United States of Amerika: Johnn Wiley and Sons, Inc.

Sari, Desi Kurnia. 2016. Perhitungan Premi Asuransi Jiwa Endowment Suku Bunga Vasicek Dengan Simulasi Monte Carlo. Skripsi. Universitas Udayana Denpasar

Sembiring, R. 1986. Buku Materi Pokok Asuransi I Modul 1-5. Jakarta: Karunika. 